\title{
Analisis Prinsip Layout and Composition pada Web Design Perusahaan PT. Bank Rakyat Indonesia, Tbk dan PT. FIF Group berdasarkan Buku "The Principle of Beautifull Website Design (2nd Edition) By Jason Beaird”
}

\author{
Heri Kuswanto \\ Pendidikan Teknik Elektronika dan Informatika \\ Program Pascasarjana UNY \\ Email: heriku@outlook.com
}

\begin{abstract}
ABSTRAK
Kajian ini bertujuan untuk mengetahui prinsip-prinsip desain web yang menarik berdasarkan buku "The Principle of The Beatiful Website Design (2nd edition) by Jason Beaird yang difokuskan pada prinsip Layout and Composition, sekaligus menjawab apakah perusahaan yang memiliki divisi IT menerapkan prinsip tersebut. Metode yang digunakan adalah pendekatan studi kasus, dengan tujuh variabel yakni web page anatomy, grid theory, balance, unity, emphasis, fresh trend dan resizing: fixed, fluid, or responsive layouts. Kajian dilakukan dengan menganalisis dan membandingkan dua buah website perusahaan nasional dengan hasil yang menunjukkan bahwa rancangan website lebih dipengaruhi oleh faktor pandangan dari sisi kegunaan dan estetika.
\end{abstract}

Kata Kunci: Prinsip Desain Website, Layout, Composition

\section{PENDAHULUAN}

Pesatnya perkembangan teknologi informasi telah menjadi salah satu bagian penting dalam kehidupan manusia. Bahkan dapat dikatakan bahwa penyebaran informasi sudah menjadi kebutuhan di segala bidang, tidak terkecuali dalam bidang ekonomi, pendidikan, kesehatan, kebudayaan, keagamaan, dan lain sebagainya. Salah satu cara menyampaikan informasi yaitu dengan media internet. Selain memiliki kecepatan dalam penyebaran informasi, internet juga merupakan media yang mudah diterima. Melalui internet berbagai bentuk aktivitas dapat dilakukan, mulai dari hal-hal yang bersifat biasa saja hingga yang berkaitan dengan aktivitas bisnis. Perusahaan akan lebih mudah menawarkan produk barang dan jasa yang dihasilkan melalui website.

Website adalah kumpulan dari halamanhalaman yang berisi informasi melalui jalur internet yang diakses melalui berbagai perangkat di seluruh dunia. Halaman tersebut merupakan komponen-komponen yang terdiri dari beberapa unsur, yakni teks, gambar, audio, video, dan animasi dari berbagai bentuk sehingga menjadi media informasi yang menarik untuk dikunjungi.

Dewasa ini, website digunakan sebagai media informasi dan promosi oleh perusahaan, lembaga pemerintah, organisasi swasta serta lembaga-lembaga pendidikan. Website yang dimiliki tentu harus memiliki karakteristik yang mewakili visi sebuah perusahaan, lembaga pemerintah atau organisasi swasta. Website sendiri dapat dikatakan sebagai sebuah kantor virtual (virtual office) sehingga perlu di desain sebagus mungkin agar pengunjung merasa nyaman mencari informasi mengenai perusahaan dan produk yang ditawarkan.

Dampak perkembangan perangkat (device) dewasa ini berimbas pada desain website agar dapat memenuhi kebutuhan pengguna. Orang ingin mengakses perusahaan dan organisasi dari berbagai macam perangkat termasuk komputer desktop (Landa, 2006). Hal ini akan mempengaruhi proses desain yang sesuai dengan prinsip-prinsip web design agar terlihat bagus dan mampu memberikan pengalaman berbeda bagi pengunjung website tersebut. Website yang bagus terdiri dari elemen-elemen yang saling berkaitan dan 
mampu menciptakan keseimbangan pada elemen tersebut (Beaird, 2010).

Menurut Beairad (2010) terdapat beberapa prinsip yang harus diperhatikan dalam proses desain website di antaranya adalah layout dan composition, color, texture, typography, dan imagery. Kajian ini akan menganalisis dan membandingkan website perusahaan yang memiliki divisi IT dalam perusahaan. Analisis yang akan dilakukan dibatasi pada unsur layout dan composition mencakup web page anatomy, grid theory, balance, unity, emphasis, fresh trend dan resizing: fixed, fluid, or responsive layouts. apakah website perusahaan tersebut menggunakan prinsip layout dan composition yang benar dalam mendesain website?

Teknologi informasi merupakan tulang punggung keberhasilan manajemen sebuah perusahaan, biasanya digunakan untuk mengelola sumber daya perusahaan maupun untuk keperluan pemasaran hasil produk barang atau jasa. Salah satu bentuk sarana pemasaran produk perusahaan adalah penyebaran informasi menggunakan website. desain website yang menarik menjadi sangat penting agar tujuan perusahaan mudah dipelajari dan dapat diterima oleh calon konsumen khususnya dalam merancang tampilan (interface). Untuk memenuhi kebutuhan pengguna (user), desain website harus memenuhi prinsip-prinsip perancangan layout dan composition dalam membangun tampilan (interface) website.

Menurut Beairad (2010) terdapat dua sudut pandang utama dari sebagian orang dalam menentukan apakah desain website dikatakan baik atau buruk yakni dari sudut pandang kegunaan yang berfokus pada fungsi, penyajian informasi yang efektif dan efisiensi, dan sudut pandang dari estetika meliputi presentasi, animasi, dan grafis yang bagus. Dengan demikian, website dikatakan baik apabila desainer dapat mengombinasi kedua sudut pandang tersebut, tidak hanya dari sudut pandang kegunaan tetapi juga dari sisi estetikanya.

Lebih lanjut lagi, pengguna akan merasa senang dengan website yang memasukkan konten dalam desainnya. developer dapat melakukan hal tersebut dengan merancang website berdasarkan kaidah layout dan composition meliputi web page anatomy, grid theory, balance, unity, emphasis, fresh trend dan resizing: fixed, fluid, or responsive layouts.

\section{Web Page Anatomy}

Dalam merancang website terdapat batasan-batasan yang menyebabkan beberapa rancangan dan kaidah secara struktur dapat muncul seperti header, navigation, content area dan sidebar, footer dan terkadang background (Miller, 2013). Sedangkan Beairad (2010) menyimpulkan bahwa meskipun terdapat beberapa blok, ukuran dan judul website, namun sebagian besar website memiliki komponen yakni container, logo, navigation, content, footer, dan whitespace.

\section{Grid Theory}

Grid system merupakan suatu kerangka yang membantu desainer grafis mengorganisasi informasi teks atau gambar secara konsisten, bermakna, dan logis dalam sebuah halaman. Penggunaan Grid system adalah sebagai solusi dari permasalahan ruang, mengelola ruang menjadi lebih terstruktur menurut hierarki visual sehingga informasi lebih bersifat komunikatif (BiteBrands, 2010). Sementara Josef Miller (1961) menyatakan bahwa grid system adalah sebuah bantuan, bukan sebuah jaminan, yang membolehkan beberapa kemungkinan untuk digunakan dan setiap desainer dapat mencari solusi yang tepat untuk personal style nya (Beaird, 2010).

\section{Balance}

Balance merupakan keadaan atau kesamaan antara kekuatan yang saling berhadapan dan menimbulkan adanya kesan seimbang secara visual. Konsep keseimbangan visual adalah kesamaan sesuatu secara fisik yang digambarkan dengan domplengan. Jika elemen pada sisi lain dari sebuah layout memiliki ukuran yang sama, maka itu disebut satu keseimbangan dengan yang lainnya (Beaird, 2010). Terdapat dua macam 
keseimbangan visual yaitu keseimbangan simetris dan keseimbangan asimetris.

Keseimbangan simetris atau keseimbangan formal terjadi ketika sebuah komposisi memiliki elemen yang sama dengan salah satu sisi pada sebuah garis sumbu. Keseimbangan simetris dibagi menjadi dua yakni; simetri bilateral yang terjadi ketika sebuah komposisi menjadi seimbang pada lebih dari satu sumbu, simetri radial yaitu simetri yang terjadi ketika elemennya sama dari titik pusat. Keseimbangan asimetris atau keseimbangan informal yang meliputi perbedaan ukuran, bentuk, warna, isi, posisi, tekstur, dan arah mata.

\section{Unity}

Teori desain menggambarkan Unity sebagai cara di mana unsur-unsur yang berbeda dari komposisi berinteraksi satu sama lain. Terdapat dua pendekatan untuk mencapai unity dalam sebuah layout yaitu: kedekatan (proximity) dan pengulangan (repetition) (Beaird, 2010). Pendekatan proximity, yaitu pengelompokan item-item yang berkaitan, mendekatkan item-item yang berkaitan, dan pengelompokan item-item yang berkaitan menjadi satu kelompok yang kohesif. Sedangkan pendekatan repetition adalah pengulangan beberapa aspek desain di keseluruhan bagian, dapat juga disebut konsistensi (Telkom University, 2016).

\section{Emphasis}

Penekanan (Emphasis) adalah tentang bagaimana membuat fitur tertentu untuk menarik perhatian pengguna (Beaird, 2010). Emphasis dimaksudkan untuk menarik perhatian pebaca atau orang yang melihat desain website, penekanan disitilahkan juga sebagai COI (center of interest) (Telkom University, 2016). Prinsipnya bisa dilakukan dengan cara: penempatan (placement), berkelanjutan (continuance), isolasi (isolation), kontras (contrast), proporsi dan (proportion) (Beaird, 2010). Pada website dapat diterapkan dengan cara pembuatan kotak raster atau keynote dengan border, ukuran font yang cukup mencolok, serta pembuatan kontras pada tekstur, warna, garis, ruang, dan pada bentuk atau motif.

\section{Fresh Trend.}

Dalam menentukan layout dan composition juga memperhatikan style yang menjadi tren saat ini. Beberapa tren yang sering digunakan dalam website yakni navigationless magazine style, expansive footers, bare-bones minimalism.

\section{Resizing: Fixed, Fluid, or Responsive} Layouts

Perangkat yang digunakan untuk mengakses website terkadang berbeda dengan ukuran layar yang berbeda juga tergantung pada device yang digunakan. Developer tentu sudah memahami hal ini, sehingga website yang diakses dapat menyesuaikan dengan perangkat yang digunakan. Oleh karena itu, desain responsice layouts sebagai sebuah alternatif. Menurut (Marcotte, 2011) responsive architecture merupakan arsitektur tergolong baru, namun lebih interaktif dari pada arsitektur yang sudah ada dan sebagian besar menjadi cara yang menarik.

\section{METODE}

Teknik sampling menggunakan purposive random sampling, yang menjadi subjek kajian pada studi ini adalah website perusahaan nasional yang bergerak dalam bidang keuangan yaitu laman PT. Bank Rakyat Indonesia, Tbk yang beralamat https://bri.co.id dan laman PT. FIF Group yang beralamat http://fifgroup.co.id .Kedua perusahaan jasa keuangan tersebut merupakan salah satu perusahaan terbesar di Indonesia dan masingmasing perusahaan memiliki divisi IT.

Pendekatan yang digunakan pada studi ini adalah pendekatan kualitatif dengan metode studi kasus, adapun yang menjadi variabelnya berdasarkan pada prinsip-prinsip desain website bagus dari buku "The Principles of Beautiful Web Design (2nd Edition) by Jason Beaird". 
Terdapat beberapa elemen dalam prinsip desain web yang menarik antara lain; Layout and composition, color, texture, typography, dan imagery. Namun kajian ini difokuskan pada elemen Layout and Composition yang mencakup web page anatomy, grid theory, balance, unity, emphasis, fresh trend dan resizing: fixed, fluid, or responsive layouts.

\section{PEMBAHASAN}

\section{PT. Bank Rakyat Indonesia}

Bank Rakyat Indonesia (BRI) adalah salah satu bank milik pemerintah yang terbesar di Indonesia yang berdiri sejak tanggal 16 Desember 1895 yang kemudian dijadikan sebagai hari kelahiran BRI (Bank Rakyat Indonesia, 2012). Website Bank Rakyat Indonesia dapat diakses melalui laman https://bri.co.id, berikut halaman beranda website BRI.

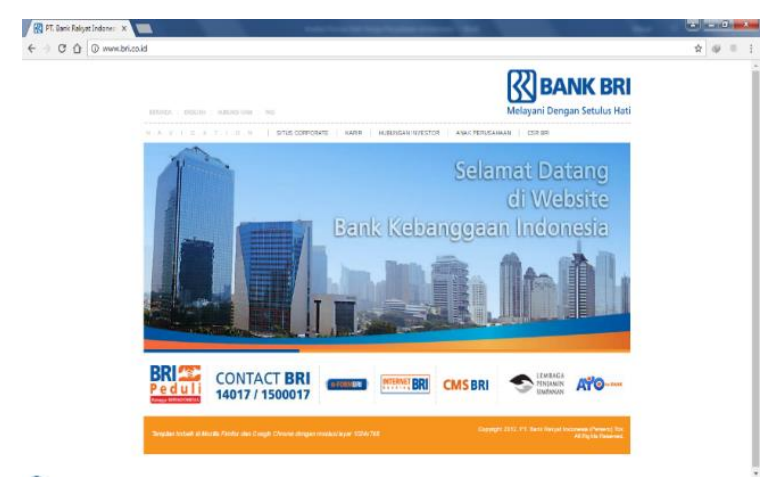

Gambar 1. Homepage Bank Rakyat Indonesia

Berdasarkan gambar 1. tampilan homepage Bank Rakyat Indonesia dapat digambarkan bentuk web page anatomy yang digunakan pada website tersebut yakni terdiri dari container, logo, header, navigation, footer, dan whitespace (background). Pada halaman beranda website ini menampilkan content dalam bentuk menu layanan yang disediakan sebagai produk jasa yang ditawarkan oleh perusahaan.

Grid system yang digunakan menggunakan grid horizontal yakni blok-blok elemen website tersusun dari bentuk persegi memanjang secara mendatar. Blok-blok tersebut dibentuk berdasarkan keseimbangan dengan pendekatan keseimbangan asimetris, dapat dilihat dari ukuran blok-blok yang berbeda secara proporsional.

Prinsip Unity digambarkan dengan pendekatan proximity di mana item-item dikelompokkan berdasarkan jenis layanan jasa yang ditawarkan oleh perusahaan. Penekanan (emphasis) yang diterapkan cukup kontras (contrast) dan proporsi (proportion) sesuai dengan warna lambang perusahaan.

Tren website tersebut juga menggambarkan bare-bones minimalism dengan menampilkan elemen-elemen penting website yang terkait dengan produk layanan yang ditawarkan perusahaan. Namun, website BRI tidak didesain dengan responsive architecture sehingga tidak ada penyesuaian terhadap perangkat yang digunakan ketika halaman website diakses dari perangkat yang berbeda, seperti pada gambar 2. tampilan homepage BRI yang diakses melalui perangkat smartphone.



Gambar 2. Homepage BRI dari smartphone

Pada gambar 2 tersebut terlihat jelas terdapat space yang kosong, disebabkan karena perangkat smartphone memiliki ukuran layar yang berbeda.

\section{PT. FIF Group}

FIF Group adalah grup manajemen dari beberapa perusahaan yang memiliki unit bisnis yang berbeda-beda. FIF Group saat ini menaungi PT. Federal Internasional Finance dan PT. Astra Multi Finance. FIF Group 
bergerak di bisnis layanan pembiayaan dengan metode pembiayaan konvensional dan syariah (FIFGRoup, 2013). Website FIF Group dapat diakses melalui laman http://fifgroup.co.id, berikut gambar tampilan hompage FIGFGroup:
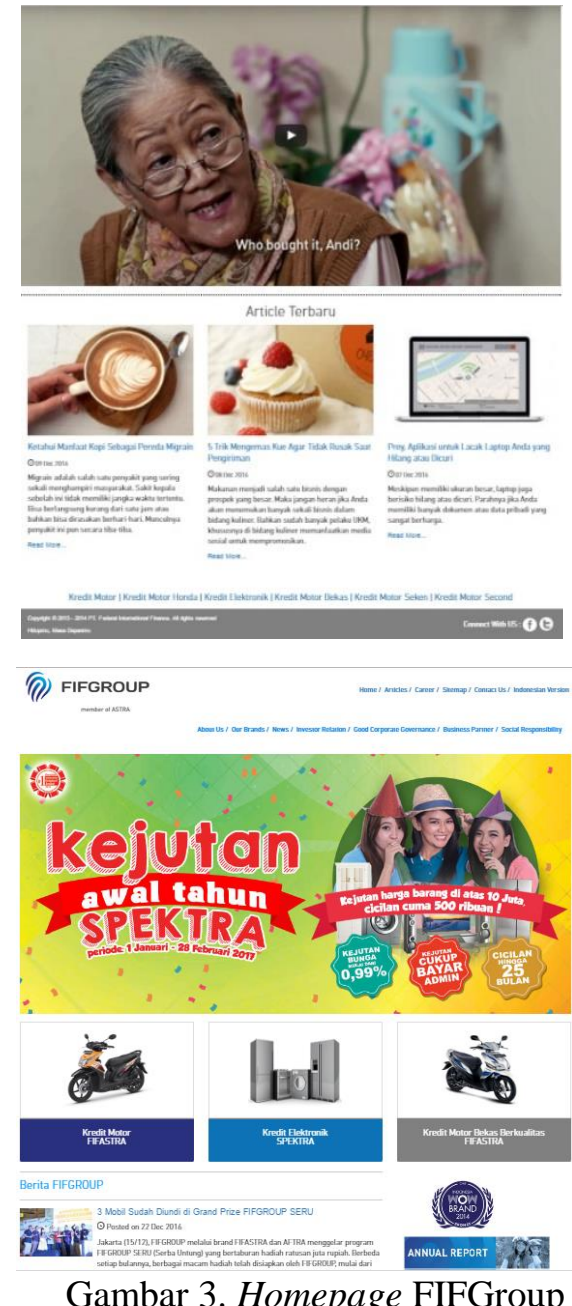

Berdasarkan Gambar 3. Tampilan homepage FIF Group di atas, web page anatomy diidentifikasikan mencakup container, logo, header, navigation, content, footer, dan whitespace (background). Berbeda dengan website BRI, website FIF Group menampilkan content yang cukup kompleks, tidak hanya mengenai produk layanan yang ditawarkan tetapi content nya memuat artikel dan berita terkait aktivitas perusahaan.

Pengaturan blok-blok elemen menggunakan modular grid yang terdiri dari grid vertical dan grid horizontal atau disebut juga dengan grid modular. Penggunaan space cukup sederhana karena terdapat space kosong yang sebenarnya dapat diisi pada right sidebar.

Prinsip Unity menggunakan pendekatan repetatioin yakni pengulangan beberapa aspek desain pada elemen-elemen tertentu. Penekanan (emphasis) dilakukan dengan cara penempatan (placement), berkelanjutan (continuance), dan proporsi (proportion). Namun, tampilan homepage tersebut belum memaksimalkan sisi yang kontras (contrast) terhadap pemilihan warna pada desainnya.

Tren website sudah mengikuti perkembangan yakni dengan navigationless magazine style. Model yang digunakan ini memberikan space yang cukup untuk menampilkan content yang beragam dan kompleks. Selain menerapkan tren baru, website FIF Grup juga menerapkan desain yang responsive, sehingga cukup baik untuk diakses melalui berbagai macam perangkat, baik perangkat desktop maupun mobile device. Berikut ditampilkan hompage FIF Group yang diakses melalui perangkat smartphone. 


\section{+}
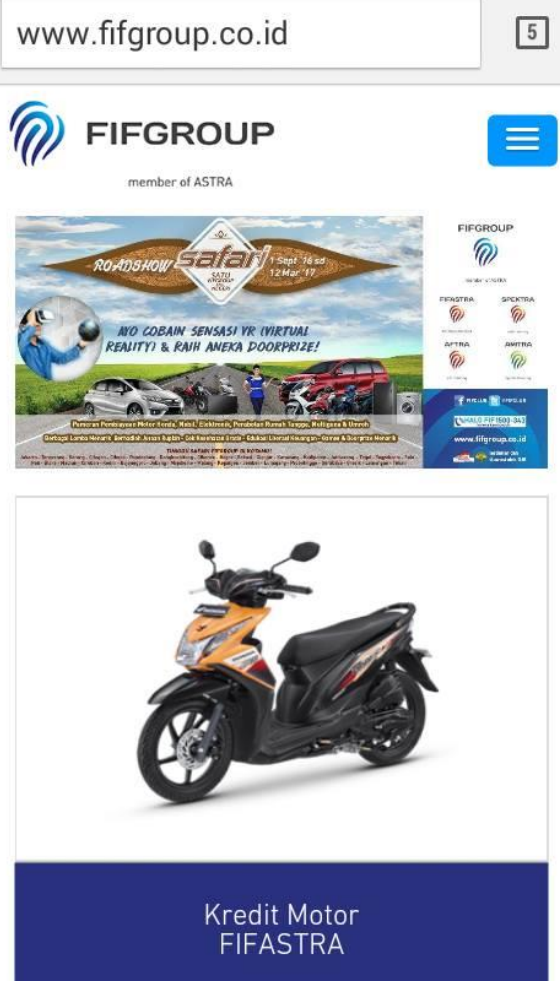

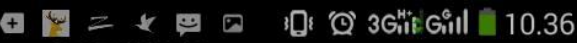

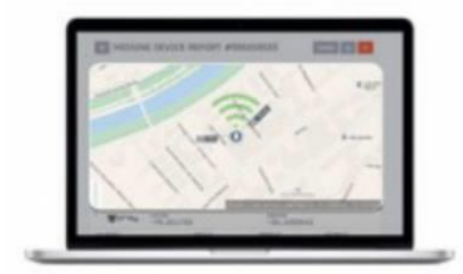

Prey, Aplikasi untuk Lacak Laptop Anda yang Hilang atau Dicuri

๑) 07 Dec 2016

Kredit Motor | Kredit Motor Honda | Kredit Elektronik | Kredit Motor Bekas I Kredit Motor Seken I Kredit Motor Second

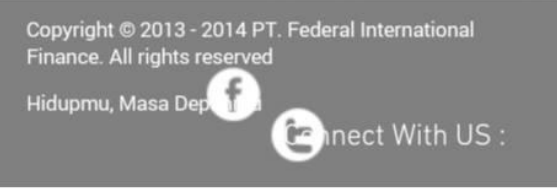

Gambar 4. Tampilan homepage fif group

\section{SIMPULAN}

Berdasarkan uraian di atas, diperoleh kesimpulan bahwa website perusahaan yang memiliki divisi IT memiliki perbedaan penerapan prinsip dalam desainnya. Hal ini disebabkan oleh beberapa faktor, salah satunya adalah pandangan apa yang berpengaruh terhadap rancangan website tersebut. Website BRI lebih menonjolkan kegunaan (usability) dari pada aspek estetika. Berbeda dengan website FIF Group, cukup memperhatikan kedua aspek tersebut meskipun terdapat beberapa pendekatan yang masih kurang.

\section{DAFTAR RUJUKAN}

Bank Rakyat Indonesia. (2012). Sejarah BRI. Retrieved from Bank Rakyat Indonesia: https://bri.co.id/articles/9

Beaird, J. (2010). The Principles of Beautiful Web Design (2nd Edition). Canada: SitePoint Pty Ltd.

BiteBrands. (2010, April 20). Grid, Metode untuk Menciptakan Komposisi Desain yang Harmonis. Retrieved from http://www.bi tebr ands.co/2010/04/semua-berawal-darigrid.html

FIFGRoup. (2013). Profil Perusahaan. Retrieved from FIFGroup: http://fifgroup.co.id/fifgroup/pages/pro fil-perusahaan (diakses Senin, 09 Januari 2017)

Landa, R. (2006). Graphic Design Solutions (5th Edition). United States of America: Wadsworth Cengage Learning.

Marcotte, E. (2011). Responsive Web Design. New York: A Book Apart.

Miller, B. (2013, September 09). Above The Fold: Understanding the Principles of Successful Web Site Design. Retrieved from Anatomy of a webpage: http://content.h-otgraphics.com/hot/anatomy-of-awebpage.pdf (diakses kembali Senin, 09 Januari 2017) 
Telkom University. (2016, Februari 01). Aplikasi Desain Web: Prinsip Desain dan Layout. Retrieved from Prodi D3 Manajemen Informatika: http://tambunan.staff.telkomuniversity .ac.id/files/2016/01/3-PRINSIP-
DESAIN-LAYOUT-SELEKSI-

lagi.pdf (diakses Senin, 09 Januari 2017) 